\title{
Economic Efficiency in Edgeworth Box Market the Case of Two Goods
}

\author{
Prof. As. Dudi SULI ${ }^{1}$, MSc Eriona DEDA ${ }^{2}$, MSc Hergys SULI ${ }^{3}$
}

\begin{abstract}
ABSRACT:
Is very important for our markets, an appreciation for some of benefits of trade and understanding to how prices get established in simple markets.

The Edgewrth box serves to orient the markets scientifically and at the same time can be used by decision makers in the planning resources process to meet customer demand. Using a production Edgewrth box, shows that efficiency in production has similar properties to efficiency in distribution.

From the optimal choices inside the Edgeworth box, we derive a production possibilities frontier that describes all the efficient combinations of two goods to maximize the benefit of both consumers. The Edgewrth box serves to orient the markets scientifically and at the same time can be used by decision makers in the planning resources process to meet customer demand. To analyze efficiency in production we use Edgeworth box. In the Edgeworth box, we analyze how the market achieves a competitive equilibrium.
\end{abstract}

Keywords: Edgeworth box, the efficient production set, competitive equilibrium, efficiency

\section{Introduction}

\section{Efficiency in production}

Is very important for our markets, an appreciation for some of benefits of trade and understanding to how prices get established in simple markets. The Edgewrth box serves to orient the markets scientifically and at the same time can be used by decision makers in the planning resources process to meet customer demand

decision makers can be:

${ }^{1}$ Department of Agricultural Political Economy, ${ }^{2}$ Department of Economics and Agribusiness of Tirana. Agricultural University of Tirana, Albania

${ }^{3}$ Plus Communication, Tirana, Albania 
i. Firms who have product delivery activities.

ii. Policy-makers, who by evaluating available resources and tools that they have available, decides on how to fulfill this requirement, as to maximize the benefit of consumers

If these requirements cannot cope on with disposal resources, then can predict the amount necessary that Must imported, and if the available resources exceed the requirements, then they may decide in that part of the excess to export. In this way resources are used efficiently economy.

"Microeconomic reform" are policies that aim to reduce market distortion economic distortions via deregulation, and increase economic efficiency. However, there is no clear theoretical basis for the belief that removing a market distortion will always increase economic efficiency.

\section{The Production Edgeworth Box}

Using a production Edgewrth box , shows that efficiency in production has similar properties to efficiency in distribution.

From the optimal choices inside the Edgeworth box, we derive a production possibilities frontier that describes all the efficient combinations of two goods to maximize the benefit of both consumers.

The Edgeworth box serves to orient the markets scientifically and at the same time can be used by decision makers in the planning resources process to meet customer demand.

To analyze efficiency in production we use Edgeworth box.

In the Edgeworth box, we analyze how the market achieves a competitive equilibrium.

To analyze efficiency in production, we use a production Edgeworth box.

In using this technique in production, we assume there are given quantities of labor and capital to be allocated to the production of $\mathrm{X}$ and $\mathrm{Y}$.

The production function of $\mathrm{x}$ and $\mathrm{y}$ are given by

$\mathrm{X}=\mathrm{X}(\mathrm{Kx}, \mathrm{Lx})$ and $\mathrm{Y}=\mathrm{Y}(\mathrm{Ky}, \mathrm{Ly})$

Where

$$
\begin{gathered}
\mathrm{Kx}+\mathrm{Ky}=\mathrm{K}=\text { maximum capital available } \\
\mathrm{Lx}+\mathrm{Ly}=\mathrm{L}=\text { maximum labor available }
\end{gathered}
$$

In the consumtion Edgeworth box, the lower left corner is one consumer`s zero consumption point and the upper right corner is the other consumer's zero consumption point.

In the production Edgeworth box, the lower left corner represents zero output of one good, while the upper right corner represents zero output of the other good. 
A movement from lower left to upper right represents an increase in output of the first good and a reduction in output of the second.

\section{The Efficient Production Set.}

In the consumption Edgeworth box, we started at an initial endowment to consumers and then analyzed how the market achieved a competitive equilibrium.

In consumption, it is not possible to make one person better off without making another person worse off when the indifference curves are tangent inside the Edgeworth box.

We will refer to the set of all points of tangency as the efficient production set. These points represent all the efficient allocations of inputs to the production of $\mathrm{X}$ and $\mathrm{Y}$.

If isoquants are tangent to one other, the marginal rates of technical substitution are equal.

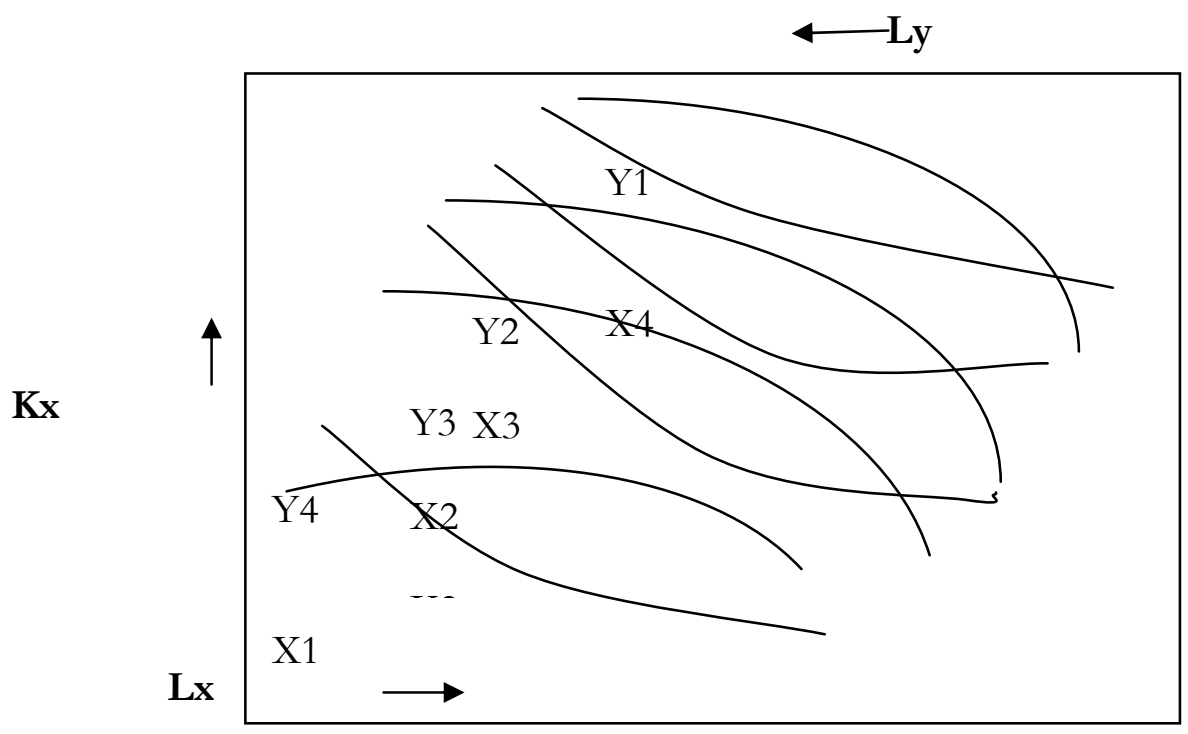

Ky

Figure 1

This is equivalent to saying that the rations of marginal products are equal between goods.

MRTSx $=$ MRTSy

$\longrightarrow$ MPLx $/$ MPKy $=$ MPLy/MPKy

An Example to show mathematically that the marginal rates of technical substitution are equal or the two goods, we maximize the production of one 
good (say X) subject both to constraintthaty is no lessthan some given amount and to the input constraints.

(This is comparable to maximizing one consumer`s utility subject both to the constraint that the other`s utility is madeno lower than some level andto thequantities of $\mathrm{X}$ an $\mathrm{Y}$ available for distribution.)

\section{Efficiency in Production}

We can combine the three constraints by substituting the input in th $y$ production function.

$\mathrm{Y}=\mathrm{y}(\mathrm{K}-\mathrm{Kx}, \mathrm{L}-\mathrm{Lx})$

This equation indicates that we can solve for an efficientproduction set for two goods.

\section{Allocative and Productive Efficiency}

Allocative efficiency is a type of economic efficiency in which economy/producers produce only those types of goods and services that are more desirable in the society and also in high demand. According to the formula the point of allocative efficiency is a point where marginal benefit is equal to marginal cost $(\mathrm{MB}=\mathrm{MC})$. At this point the social surplus is maximized with no deadweight loss, or the value society puts on that level of output produced minus the value of resources used to achieve that level, yet can be applied to other things such as level of pollution. Free markets under perfect competition generally are allocatively efficient, yet are not for the cases of monopoly, monopsony, externalities, and public goods which construe market failure, or price controls which construe government failure in addition to taxation. Allocative efficiency is the main tool of welfare analysis to measure the impact of markets and public policy upon society and subgroups being made better or worse off.

Although there are different standards of evaluation for the concept of allocative efficiency, the basic principle asserts that in any economic system, choices in resource allocation produce both "winners" and "losers" relative to the choice being evaluated. The principles of rational choice, individual maximization, utilitarianism and market theory further suppose that the outcomes for winners and losers can be identified, compared and measured.

Under these basic premises, the goal of maximizing allocative efficiency can be defined according to some neutral principle where some allocations are objectively better than others. For example, an economist might say that a change in policy increases allocative efficiency as long as those who benefit from the change (winners) gain more than the losers lose.

Allocative and Productive Efficiency 
A market can be said to have allocative efficiency if the price of a product that the market is supplying is equal to the value consumers place on it, represented by marginal cost. When drawing diagrams for firms, allocative efficiency is satisfied if the equilibrium is at the point where marginal cost is equal to average revenue. This is the case for the long run equilibrium of perfect competition.

Productive efficiency is when units of goods are being supplied at the lowest possible average total cost. When drawing diagrams for firms, this condition is satisfied if the equilibrium is at the minimum point of the ATC curve. This is again the case for the long run equilibrium of perfect competition.

\section{The competitive equilibrium.}

In a competitive equilibrium, supply equals demand. Property P1 is satisfied, because at the equilibrium price the amount supplied is equal to the amount demanded. Property P2 is also satisfied. Demand is chosen to maximize utility given the market price: no one on the demand side has any incentive to demand more or less at the prevailing price. Likewise supply is determined by firms maximizing their profits at the market price: no firm will want to supply any more or less at the equilibrium price. Hence, agents on neither the demand side nor the supply side will have any incentive to alter their actions.

To see whether Property P3 is satisfied, consider what happens when the price is above the equilibrium. In this case there is an excess supply, with the quantity supplied exceeding that demanded. This will tend to put downward pressure on the price to make it return to equilibrium. Likewise where the price is below the equilibrium point there is a shortage in supply leading to an increase in prices back to equilibrium. Not all equilibria are "stable" in the sense of Equilibrium property P3. It is possible to have competitive equilibria that are unstable. However, if an equilibrium is unstable, it raises the question of how you might get there. Even if it satisfies properties P1 and P2, the absence of P3 means that the market can only be in the unstable equilibrium if it starts off there.

In most simple microeconomic stories of supply and demand a static equilibrium is observed in a market; however, economic equilibrium can be also be dynamic. Equilibrium may also be economy-wide or general, as opposed to the partial equilibrium of a single market. Equilibrium can change if there is a change in demand or supply conditions. For example, an increase in supply will disrupt the equilibrium, leading to lower prices. Eventually, a new equilibrium will be attained in most markets. Then, there will be no change in price or the amount of output bought and sold - until there is an exogenous shift in supply or demand (such as changes in technology or tastes). That is, there are no endogenous forces leading to 
Figure 2

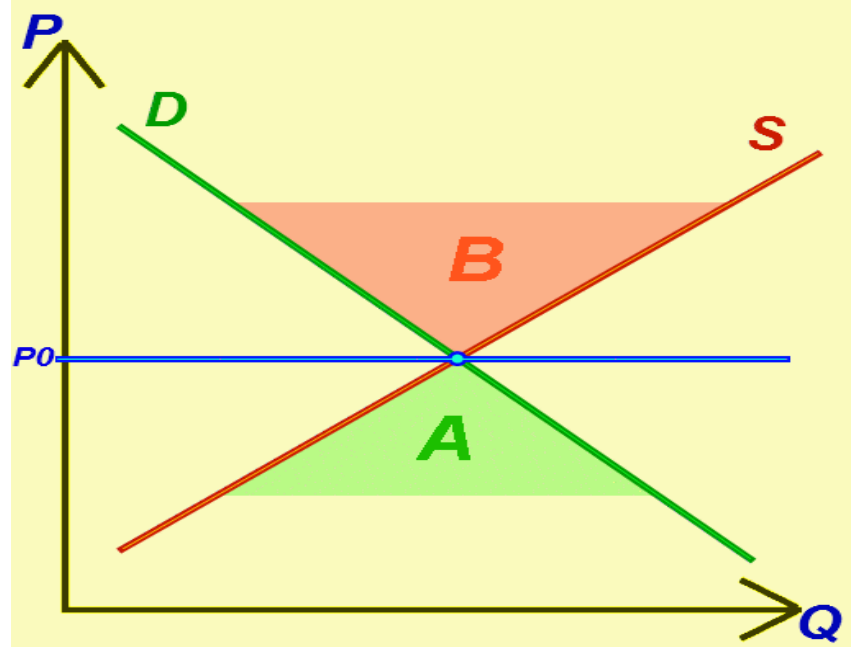

The price or the quantity.

Price of market balance:

$\mathrm{P}$ - price

Q - quantity demanded and supplied

$\mathrm{S}$ - supply curve

$\mathrm{D}$ - demand curve

P0 - equilibrium price

A - excess demand - when $\mathrm{P}<\mathrm{P} 0$

B - excess supply - when $\mathrm{P}>\mathrm{P} 0$

\section{Pareto efficiency}

Pareto efficiency, or Pareto optimality, is a concept in economics with applications in engineering. The term is named after Vilfredo Pareto (18481923), an Italian economist who used the concept in his studies of economic efficiency and income distribution. Pareto efficiency is a state of economic allocation of resources in which it is impossible to make any one further better off without making at least one individual worse off. Given an initial allocation of goods among a set of individuals, a change to a different allocation that makes at least one individual better off without making any other individual worse off is called a Pareto improvement.

\section{References}

Alexander, W. R. J. (1997). "Inflation And Economic Growth: Evidence from a Growth Equation.” Applied Economics, Vol. 29:233-238.

Bruno, M. and W. Easterly (1996). "Inflation and Growth: In Search of Stable Relationship." Federal Reserve Bank of St. Louis Review, Vol. 78, No.3. Fischer, S. (1993). "The Role of Macroeconomic Factors in Growth."

Journal of Monetary Economics, Vol.32: 485-512.

Ghosh, A. and S. Philip (1998). Inflation, Disinflation, and Growth. IMF Working Paper No.WP/98/68. Washington, D.C.: IMF.

Mahmood, B., Saba, A., Khaliq, M., \& Hussain, S. Employment Opportunities for the Certificate Holders: an Analysis of New Social Milieu in the Context of Banking Sector of Pakistan. Mediterranean Journal of Social Sciences, 2. 